\title{
Anatomia do lenho de espécies do gênero Nectandra Rol. ex Rottb. (Lauraceae)
}

\author{
Carlos Wagner de Oliveira ${ }^{1}$ \\ Cátia Henriques Callado ${ }^{2}$ \\ Osnir Marquete ${ }^{3,4}$
}

\begin{abstract}
RESUMO
Neste trabalho é apresentada a descrição anatômica do lenho de Nectandra leucantha Nees, Nectandra puberula (Schott) Nees e Nectandra rigida (H. B. K.) Nees. As três espécies apresentaram camadas de crescimento distintas; porosidade difusa; parênquima axial paratraqueal; placas de perfuração simples e escalariformes; pontoações intervasculares alternas e fibras septadas. As características que se mostraram úteis para a segregação das espécies foram: tipo e distribuição do parênquima axial, formato das pontoações intervasculares e presença de células oleíferas/ mucilaginosas.
\end{abstract}

Palavras-chaves: Anatomia da madeira, Lauraceae, Nectandra, Floresta Atlântica.

\section{ABSTRACT}

The wood anatomy of Nectandra leucantha Nees, Nectandra puberula (Schott) Nees and Nectandra rigida (H. B. K.) Nees is described. The species showed distinct growth rings; diffuse porous; paratracheal axial parenchyma; simple and scalariform perforated plates; alternate intervessel pits and septate fibres. The useful characteristics for segregation the species were: type and distribution of the axial parenchyma, intervessel pits shape, presence of oil/mucilage cells.

Keywords: Wood anatomy, Lauraceae, Nectandra, Atlantic rain forest.

\section{INTRODUÇÃO}

A família Lauraceae possui cerca de 50 gêneros e aproximadamente 3.000 espécies lenhosas, distribuídas pelas regiões pantropicais, principalmente nas florestas centro e sul-americanas (Metcalfe, 1987; Rohwer, 1993; Werff \& Richter, 1996). Inúmeras espécies são ricas em substâncias aromáticas e a grande maioria tem importância econômica (madeira, óleos essenciais e frutos comestíveis) e/ou fitossociológica, devido à sua grande representatividade e ampla distribuição (Gottlieb, 1972; Klein, 1974; Rizzini, 1971).

O grau de importância das Lauraceae em remanescentes de Floresta Atlântica no estado do Rio de Janeiro faz com que a família ocupe um lugar de destaque entre aquelas de maior riqueza florística (Guedes-Bruni, 1998). O gênero Nectandra Rol. ex Rottb. é originário da América tropical e subtropical, destacandose entre os mais importantes na família, com aproximadamente 175 espécies exclusivamente centro e sul-americanas (Chacón \& Fournier, 1987; Record \& Hess, 1942).

A família constitui um dos grupos taxonômicos de maior dificuldade para a caracterização das espécies, que mesmo pertencendo a diferentes gêneros, apresentam uma acentuada uniformidade morfológica (Castiglioni, 1951, 1962; Record \& Hess, 1942; Record \& Mell, 1924). A maioria das chaves de identificação e dos estudos taxonômicos de

${ }^{1}$ Bolsista PIBIC/CNPq - Programa Mata Atlântica/Instituto de Pesquisas Jardim Botânico do Rio de Janeiro. Rua Jardim Botânico, 1008. Jardim Botânico, Rio de Janeiro - RJ. CEP: 22460-000; tel: (0xx21) 2511-0401; e-mail: carloswag@hotmail.com

${ }^{2}$ Universidade do Estado do Rio de Janeiro

${ }^{3}$ Instituto de Pesquisas Jardim Botânico do Rio de Janeiro

${ }^{4}$ Universidade Santa Úrsula 
Lauraceae estão baseados em caracteres florais (Werff, 1991). Entretanto, em função da similaridade desses caracteres nos diferentes táxons, Werff \& Richter (1996) sugeriram que os estudos taxonômicos na família sejam baseados na combinação de caracteres anatômicos da casca, do lenho e do tipo de inflorescência.

Este trabalho constitui parte de uma série de pesquisas anatômicas sobre as famílias mais representativas da Floresta Atlântica no estado do Rio de Janeiro (Programa Mata Atlântica do Instituto de Pesquisas Jardim Botânico do Rio de Janeiro) e tem como objetivos descrever a anatomia do lenho de Nectandra leucantha Nees, Nectandra rigida (H B. K) Nees e Nectandra puberula (Schott) Nees e analisar comparativamente os resultados obtidos com os descritos na literatura, a fim de verificar a importância dos estudos anatômicos do lenho para segregação de espécies e taxonomia da família.

\section{MATERIAL E MÉTODOS}

O material botânico estudado é proveniente de duas Unidades de Conservação no estado do Rio de Janeiro: Reserva Biológica de Poço das Antas e Reserva Ecológica de Macaé de Cima. A Reserva Biológica de Poço das Antas está situada no município de Silva

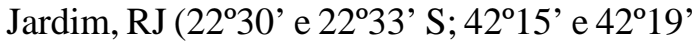
W). A topografia é predominantemente de planície, com a presença de morros e morrotes, com alturas que variam de 30 a 200 metros, separados por várzeas alagadiças. A temperatura média anual é de $24,48^{\circ} \mathrm{C}$, sendo a precipitação total anual de $2200 \mathrm{~mm}$. A vegetação local é do tipo Floresta Ombrófila Densa de Terras Baixas e Floresta Ombrófila Densa Submontana (Guedes-Bruni, 1998). A Reserva Ecológica de Macaé de Cima está situada no município de Nova Friburgo, RJ $\left(22^{\circ} 21^{\prime}\right.$ e $22^{\circ} 28^{\prime} \mathrm{S} ; 42^{\circ} 27^{\prime}$ e $\left.42^{\circ} 35^{\prime} \mathrm{W}\right)$. A topografia é fortemente ondulada, com ocorrência de pequenos vales, abrangendo altitudes de 880 a $1720 \mathrm{msm}$. A temperatura média anual é de $17,9^{\circ} \mathrm{C}$, sendo a precipitação total anual de $2128 \mathrm{~mm}$. A vegetação local é do tipo Floresta Ombrófila Densa Montana, com a ocorrência de Campos de Altitude nas porções mais elevadas, acima dos 1500 metros de altitude (Guedes-Bruni, 1998).

As espécies foram selecionadas de acordo com resultados prévios de estudos florísticos e fitossociológicos (Guedes-Bruni, 1998). Uma descrição parcial de $N$. rigida foi apresentada em Barros et al (1997). As coletas foram realizadas em indivíduos de fuste reto e sem bifurcações ou defeitos aparentes. As incisões foram realizadas à altura do peito (DAP), a aproximadamente $1,30 \mathrm{~m}$ acima do solo, de acordo com as normas e procedimentos para estudos anatômicos do lenho (Coradin \& Muñiz, 1991). O número de indivíduos analisados se deve ao critério seletivo de coleta adotado e ao tamanho das populações de cada espécie nas respectivas áreas inventariadas.

O material botânico foi processado no Laboratório de Botânica Estrutural do Instituto de Pesquisas Jardim Botânico do Rio de Janeiro de acordo com as técnicas apropriadas aos estudos anatômicos do lenho (Burger \& Richter, 1991; Johansen, 1940; Sass, 1958). A partir das amostras de madeira, foram confeccionados corpos de prova, posteriormente seccionados em micrótomo de deslizamento Jung $\mathrm{K}$, nos planos transversal e longitudinal (radial e tangencial), obtendo-se cortes com espessura média de $15 \mu \mathrm{m}$. Os testes histoquímicos foram realizados em cortes obtidos de material sem qualquer tratamento prévio, tendo sido as substâncias lipídicas evidenciadas pelo Sudan IV (Jensen, 1962; Johansen, 1940) e a presença de substâncias pécticas, pela coloração com Vermelho de Rutênio (McLean \& Cook, 1958). As mensurações foram realizadas com auxílio de ocular micrométrica acoplada ao microscópio Olympus BH-2. As descrições, contagens e mensurações dos elementos celulares obedeceram às normas determinadas pelo IAWA Committee 
Tabela 1. Espécies estudadas e seus respectivos números de registro e locais de coleta. RBw: Número de registro das amostras de madeira na Xiloteca do Instituto de Pesquisas Jardim Botânico do Rio de Janeiro. DAP: Diâmetro à altura do peito em centímetros.

\begin{tabular}{lccl}
\hline \multicolumn{1}{c}{ Espécie } & RBw & DAP $(\mathrm{cm})$ & \multicolumn{1}{c}{ Local de Coleta } \\
\hline N. leucantha & 7440 & 13,4 & Reserva Biológica de Poço das Antas \\
N. puberula & 7293 & 66,4 & Reserva Ecológica de Macaé de Cima \\
N. puberula & 7539 & 7,0 & Reserva Ecológica de Macaé de Cima \\
N. rigida & 7330 & 40,0 & Reserva Biológica de Poço das Antas \\
N. rigida & 7361 & 35,1 & Reserva Biológica de Poço das Antas \\
N. rigida & 7365 & 25,0 & Reserva Biológica de Poço das Antas \\
\hline
\end{tabular}

(1989). As amostras de madeira foram depositadas e registradas na Xiloteca do Instituto de Pesquisas Jardim Botânico do Rio de Janeiro (Tabela 1).

A análise estatística foi realizada com o Software Statistica v. 5.0 for Win95/NT e baseou-se nas 18 características qualitativas descritas na Tabela 2. A análise de variância (one-way ANOVA) foi utilizada para verificar a existência de diferenças significativas ( $<0,05$ ) entre as espécies estudadas (Tabela 3 ).

\section{RESULTADOS}

Nectandra leucantha Nees

(Figs. 1-4 e Tabela 2)

Camadas de crescimento: distintas, demarcadas pelo achatamento radial das fibras e maior espessamento de suas paredes no lenho tardio.

Elementos de vaso: porosidade difusa; (14-)19(-26) vasos $/ \mathrm{mm}^{2}$, em arranjo diagonal, solitários e múltiplos radiais de 2-4 elementos, ou em cachos de 3-6 elementos, seção circular a oval; comprimento (510-)714(-947) $\mu \mathrm{m}$, diâmetro tangencial (72-)101(-136) $\mu \mathrm{m}$; paredes com cerca de $3 \mu \mathrm{m}$ de espessura; placas de perfuração simples e escalariformes com 1-10 barras; pontoações intervasculares médias, areoladas, alternas, de formato poligonal, abertura elíptica e inclusa; pontoações raio-vasculares areoladas a aparentemente simples, arredondadas e alongadas nos sentidos horizontal e diagonal, pontoações parênquimo-vasculares semelhantes às raio-vasculares.

Fibras: septadas; comprimento (648-)1094 (-1465) $\mu \mathrm{m}$; diâmetro (19-)25(-37) $\mu \mathrm{m}$; lume (9-)19(-32) $\mu \mathrm{m}$; presença de pontoações simples nas paredes radiais; paredes delgadas a espessas.

Parênquima axial: paratraqueal vasicêntrico, raramente unilateral; em série de 2-7 células de altura, (512-)712(-895) $\mu \mathrm{m}$.

Raios: (3-)6,5(-7)/mm; unisseriados e multisseriados, 2-3 células de largura, (39-) 396(-587) $\mu \mathrm{m}$ de altura e (18-)25(-34) $\mu \mathrm{m}$ de largura, constituídos por células procumbentes na porção central e uma fileira de eretas nas margens.

\section{Nectandra puberula (Schott) Nees}

(Figs. 5-8 e Tabela 2)

Camadas de crescimento: distintas ou pouco distintas, demarcadas pelo achatamento radial das fibras e maior espessamento de suas paredes no lenho tardio.

Elementos de vaso: porosidade difusa; (6-)14(-21) vasos $/ \mathrm{mm}^{2}$, em arranjo diagonal, solitários e múltiplos radiais de 2-6 elementos, ou em cachos de 3-8 elementos, seção circular a oval; comprimento (440-)641(-930) $\mu \mathrm{m}$, diâmetro tangencial (70-)97(-148) $\mu \mathrm{m}$; paredes com cerca de $4 \mu \mathrm{m}$ de espessura; placas de perfuração simples e escalariformes com 1-8 barras; 

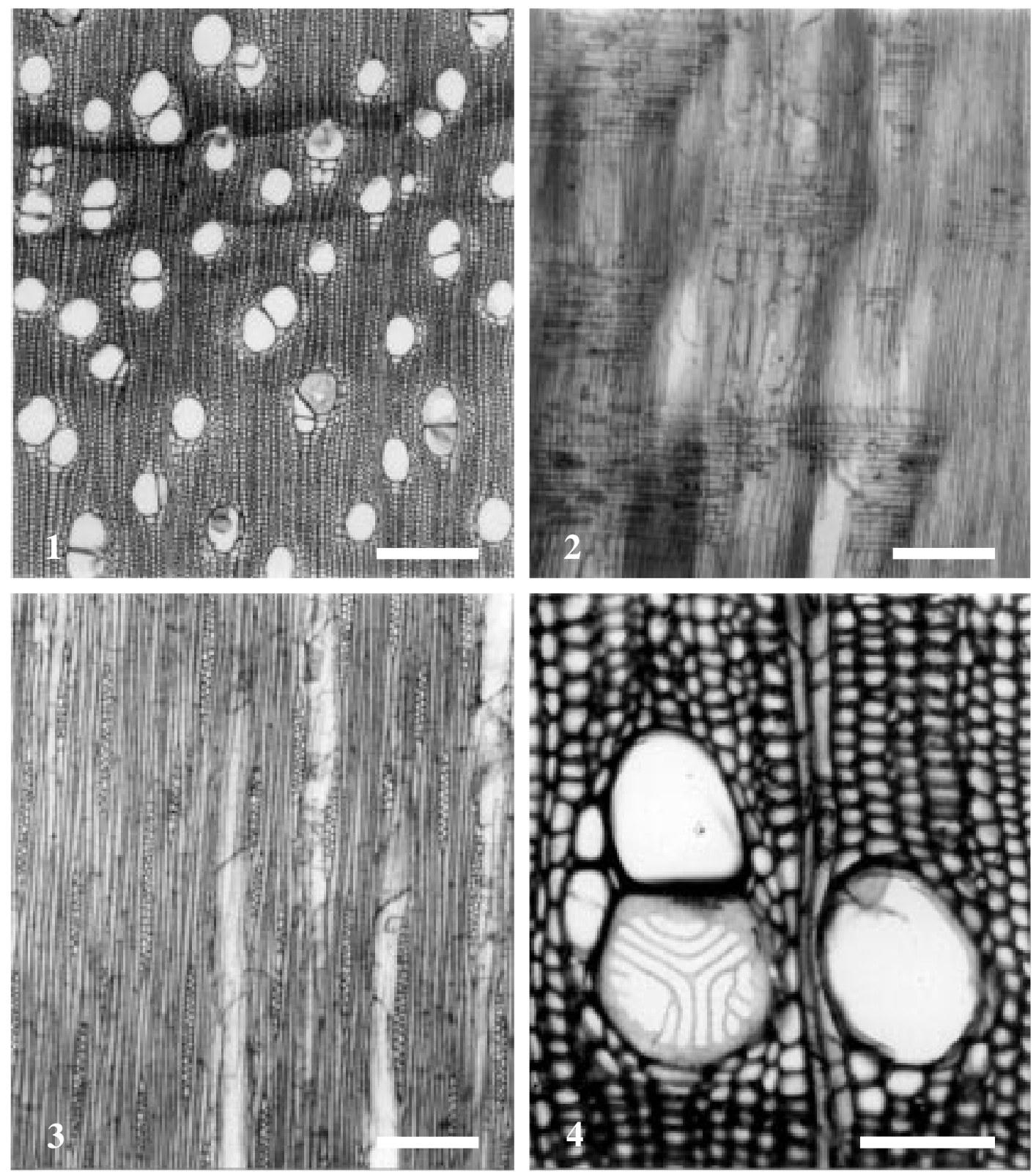

Figuras 1-4. Nectandra leucantha. Fig. 1. Seção transversal; Fig. 2. Seção longitudinal radial; Fig. 3. Seção longitudinal tangencial; Fig. 4. Seção transversal, evidenciando placa de perfuração irregular. Figuras 1, 2 e 3. Barra $=300 \mu \mathrm{m}$. Figura 4. Barra $=150 \mu \mathrm{m}$.

pontoações intervasculares grandes, areoladas, alternas, de formato poligonal, abertura elíptica e inclusa; pontoações raio-vasculares simples e areoladas, arredondadas e alongadas nos sentidos horizontal, vertical e diagonal, pontoações parênquimo-vasculares semelhantes às raio-vasculares.

Fibras: septadas; comprimento (745-)1166
(-1720) $\mu \mathrm{m}$; diâmetro (16-)24(-33) $\mu \mathrm{m}$; lume (5-)15(-26) $\mu \mathrm{m}$; presença de pontoações simples nas paredes radiais; paredes delgadas a espessas.

Parênquima axial: paratraqueal vasicêntrico, unilateral, aliforme e confluente, em série de 1-8 células de altura, (313-)578(-810) $\mu \mathrm{m}$.

Raios: (4-)6,5(-7)/mm; unisseriados e 

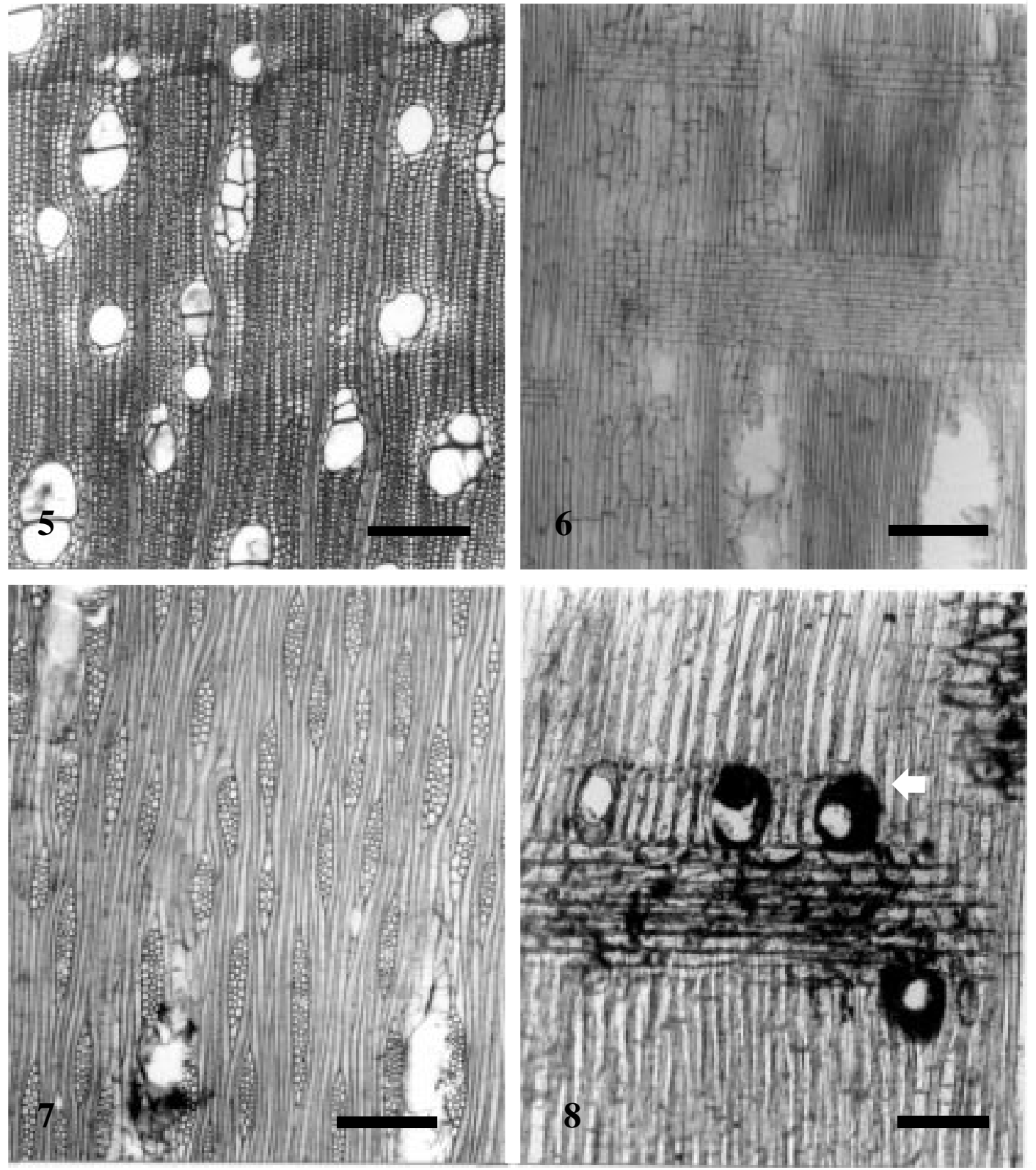

Figuras 5-8. Nectandra puberula. Fig. 5. Seção transversal; Fig. 6. Seção longitudinal radial; Fig. 7. Seção longitudinal tangencial; Fig. 8. Seção longitudinal radial, evidenciando células oleíferas/mucilaginosas $(\rightarrow)$. Figuras 5, 6 e 7. Barra $=300$ $\mu \mathrm{m}$. Figura 8. Barra $=200 \mu \mathrm{m}$.

multisseriados, 2-4 células de largura, (132-) 326(-634) $\mu \mathrm{m}$ de altura e (18-)34(-57) $\mu \mathrm{m}$ de largura, constituídos por células procumbentes na porção central e quadradas nas margens.

\section{Células oleíferas/mucilaginosas:} associadas aos parênquimas axial e radial, os testes histoquímicos constataram a presença simultânea de substâncias lipídicas e pécticas (Fig. 8).

Nectandra rigida (H. B. K.) Nees (Figs. 9-12 e Tabela 2).

Camadas de crescimento: indistintas ou distintas, demarcadas pelo achatamento radial das fibras e maior espessamento de suas 

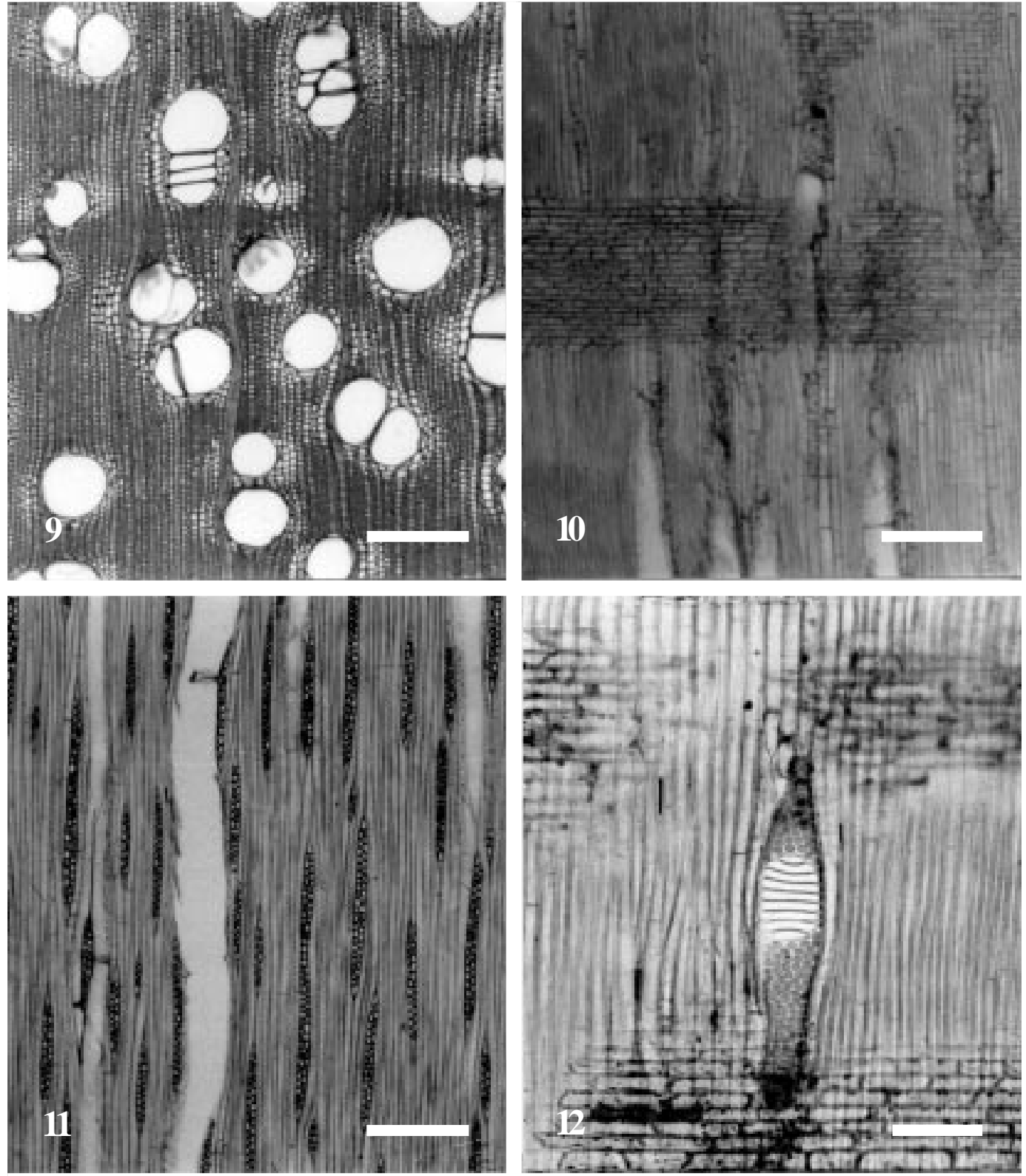

Figuras 9-12. Nectandra rigida. Fig. 9. Seção transversal; Fig. 10. Seção longitudinal radial; Fig. 11. Seção longitudinal tangencial; Fig. 12. Seção longitudinal radial, evidenciando placa de perfuração escalariforme. Figuras 9, 10 e 11. Barra $=300 \mu \mathrm{m}$. Figura 12. Barra $=200 \mu \mathrm{m}$.

paredes no lenho tardio.

Elementos de vaso: porosidade difusa; (8-)12(-20) vasos $/ \mathrm{mm}^{2}$, em arranjo diagonal, solitários, e múltiplos radiais de 2-8 elementos; ou em cachos de 3-6 elementos, seção circular a oval; comprimento (398-)726(-1103) $\mu \mathrm{m}$; diâmetro tangencial (68-)137(-235) $\mu \mathrm{m}$; paredes com cerca de $4 \mu \mathrm{m}$ de espessura, placas de perfuração simples e escalariformes com 1-8 barras, pontoações intervasculares grandes, alternas de formato circular a poligonal, abertura elíptica e inclusa; pontoações raio-vasculares levemente areoladas, alongadas nos sentidos horizontal e diagonal, pontoações parênquimo-vasculares semelhantes às raio-vasculares. 
Tabela 2. Sumário dos caracteres anatômicos referentes às três espécies estudadas neste trabalho (*) e às seis espécies descritas na literatura. 1: Alves de Pinho (1968); 2: Castiglioni (1962); 3: Luchi (1998); (+) Presente; (-) Ausente.

\begin{tabular}{|c|c|c|c|c|c|c|c|c|c|}
\hline Caracteres Anatômicos & 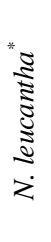 & 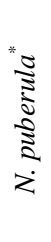 & 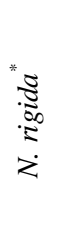 & 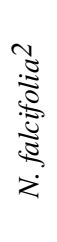 & 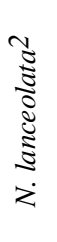 & 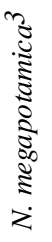 & 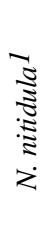 & 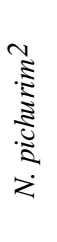 & 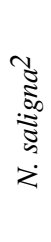 \\
\hline Porosidade difusa & + & + & + & + & + & + & + & + & + \\
\hline Pontoações intervasculares alternas & + & + & + & + & + & + & + & + & + \\
\hline Pontoações intervasculares alternas de formato poligonal & + & + & - & + & + & - & - & + & + \\
\hline Pontoações intervasculares alternas de formato circular & - & - & + & + & - & + & - & + & - \\
\hline Placa de perfuração simples & + & + & + & + & + & + & + & + & + \\
\hline Placa de perfuração escalariforme & + & + & + & + & - & - & - & + & + \\
\hline Parênquima vasicêntrico & + & + & + & - & + & - & - & - & - \\
\hline Parênquima unilateral & + & + & - & - & - & - & - & - & - \\
\hline Parênquima aliforme & - & + & + & - & - & - & - & - & + \\
\hline Parênquima confluente & - & + & + & - & - & - & - & - & - \\
\hline Parênquima escasso & - & - & - & + & + & + & + & + & - \\
\hline Raios unisseriados e multisseriados & + & + & + & + & + & + & + & + & + \\
\hline Raios fusionados & + & - & + & + & + & - & - & + & + \\
\hline Fibras septadas & + & + & + & + & + & + & + & + & + \\
\hline Fibras gelatinosas & - & - & + & - & - & + & - & - & - \\
\hline Pontoações simples das fibras & + & + & + & + & + & + & + & + & + \\
\hline Células oleíferas / mucilaginosas & - & + & - & + & + & + & + & + & + \\
\hline Cristais estilóides & - & - & - & - & - & - & - & - & + \\
\hline
\end{tabular}

Fibras: septadas; comprimento (78-)1233 (-1622) $\mu \mathrm{m}$; diâmetro (13-)21(-33) $\mu \mathrm{m}$; lume (4-)12(-23) $\mu \mathrm{m}$; presença de pontoações simples nas paredes radiais; paredes delgadas a espessas; presença de fibras gelatinosas.

Parênquima axial: paratraqueal vasicêntrico, aliforme e confluente; em série de 2-8 células de altura; (277-)694(-1392) $\mu \mathrm{m}$; presença de substâncias fenólicas.

Raios: (4-)7(-7)/mm; unisseriados (41-)165 (-281) $\mu \mathrm{m}$ de altura e (6-)12(-23) $\mu \mathrm{m}$ de largura e multisseriados, 2-4 células de largura, (158-)412(-830) $\mu \mathrm{m}$ de altura e (14-)26 (-43) $\mu \mathrm{m}$ constituídos por células procumbentes na porção central e eretas ou quadradas nas margens; presença de substâncias fenólicas e de raios agregados e fusionados.

\section{DISCUSSÃO}

A estrutura da madeira nas Lauraceae é dita como notavelmente uniforme (Richter, 1987), apresentando uma combinação de aspectos anatômicos que permitem facilmente caracterizá-la em relação às outras famílias (Stern, 1954). Dentre os mais significativos, merecem referência: raios estreitos, geralmente de 1-4 células de largura; parênquima paratraqueal presente em todas as espécies; pontoações intervasculares alternas; células oleíferas/mucilaginosas na maioria das espécies e porosidade difusa (Richter, 1987; Stern, 1954). Entretanto, a grande semelhança entre os diferentes gêneros torna difícil a identificação taxonômica do grupo (Record \& Hess, 1942).

Para o gênero Nectandra são descritos como mais constantes os seguintes caracteres anatômicos: porosidade difusa; vasos em arranjo diagonal, nunca exclusivamente solitários, sempre acompanhados por múltiplos radiais de poucos elementos; diâmetro tangencial médio de 140 a $200 \mu \mathrm{m}$; freqüência de vasos em torno de 6 a $17 / \mathrm{mm}^{2}$, pontoações intervasculares alternas médias a grandes (9 a $14 \mu \mathrm{m}$ ); placas de perfuração exclusivamente simples ou combinadas simples e escalariformes; fibras septadas de paredes delgadas a espessas, com pontoações simples, restritas às paredes radiais; parênquima axial paratraqueal; raios 
Oliveira, C. W. de, Callado, C. H., Marquete, O.

132

Tabela 3. Análise de variância entre as nove espécies de Nectandra, baseada nas 18 características qualitativas referidas na Tabela 2. As letras diferentes $(a-b)$ de cada coluna separadamente indicam diferença significativa entre as espécies a $\mathrm{p}<0,05$.

\begin{tabular}{|c|c|c|c|c|c|c|c|c|c|}
\hline & 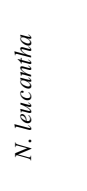 & 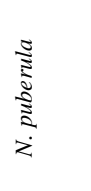 & 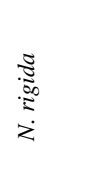 & 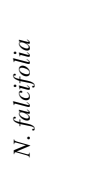 & $\begin{array}{l}\frac{\Xi}{\Xi} \\
\frac{\Xi}{\Xi} \\
\stackrel{\Xi}{\Xi} \\
\vdots \\
z\end{array}$ & 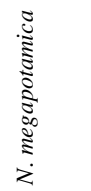 & 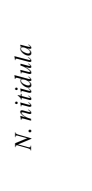 & 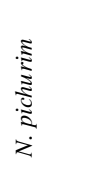 & 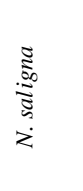 \\
\hline N. leucantha & $1,000 \mathrm{a}$ & $0,026 \mathrm{~b}$ & $0,281 \mathrm{a}$ & $0,229 \mathrm{a}$ & $0,023 \mathrm{~b}$ & $0,920 \mathrm{a}$ & $0,653 \mathrm{a}$ & $0,229 \mathrm{a}$ & $0,097 \mathrm{a}$ \\
\hline N. puberula & $0,026 \mathrm{~b}$ & $1,000 \mathrm{a}$ & $0,502 \mathrm{a}$ & $0,956 \mathrm{a}$ & $0,281 \mathrm{a}$ & $0,827 \mathrm{a}$ & $0,624 \mathrm{a}$ & $0,956 \mathrm{a}$ & $0,153 \mathrm{a}$ \\
\hline$N$. rigida & $0,281 \mathrm{a}$ & $0,502 \mathrm{a}$ & $1,000 \mathrm{a}$ & $0,281 \mathrm{a}$ & $0,956 \mathrm{a}$ & $0,440 \mathrm{a}$ & $0,624 \mathrm{a}$ & $0,281 \mathrm{a}$ & $0,729 \mathrm{a}$ \\
\hline N. falcifolia & $0,229 \mathrm{a}$ & $0,956 \mathrm{a}$ & $0,281 \mathrm{a}$ & $1,000 \mathrm{a}$ & $0,023 \mathrm{~b}$ & $0,003 \mathrm{~b}$ & $0,001 \mathrm{~b}$ & $0,001 \mathrm{~b}$ & $0,097 \mathrm{a}$ \\
\hline N. lanceolata & $0,023 \mathrm{~b}$ & $0,281 \mathrm{a}$ & $0,956 \mathrm{a}$ & $0,023 \mathrm{~b}$ & $1,000 \mathrm{a}$ & $0,073 \mathrm{a}$ & $0,014 \mathrm{~b}$ & $0,023 \mathrm{~b}$ & $0,097 \mathrm{a}$ \\
\hline N. megapotamica & $0,920 \mathrm{a}$ & $0,827 \mathrm{a}$ & $0,440 \mathrm{a}$ & $0,003 \mathrm{~b}$ & $0,073 \mathrm{a}$ & $1,000 \mathrm{a}$ & $0,001 \mathrm{~b}$ & $0,003 \mathrm{~b}$ & $0,755 \mathrm{a}$ \\
\hline N. nitidula & $0,653 \mathrm{a}$ & $0,624 \mathrm{a}$ & $0,624 \mathrm{a}$ & $0,001 \mathrm{~b}$ & $0,014 \mathrm{~b}$ & $0,001 \mathrm{~b}$ & $1,000 \mathrm{a}$ & $0,001 \mathrm{~b}$ & $0,346 \mathrm{a}$ \\
\hline N. pichurim & $0,229 \mathrm{a}$ & $0,956 \mathrm{a}$ & $0,281 \mathrm{a}$ & $1,000 \mathrm{a}$ & $0,023 \mathrm{~b}$ & $0,003 \mathrm{~b}$ & $0,001 \mathrm{~b}$ & $1,000 \mathrm{a}$ & $0,097 \mathrm{a}$ \\
\hline N. saligna & $0,097 \mathrm{a}$ & $0,153 \mathrm{a}$ & $0,729 \mathrm{a}$ & $0,097 \mathrm{a}$ & $0,097 \mathrm{a}$ & $0,755 \mathrm{a}$ & $0,346 \mathrm{a}$ & $0,097 \mathrm{a}$ & $1,000 \mathrm{a}$ \\
\hline
\end{tabular}

unisseriados e multisseriados, heterogêneos, geralmente 2-3 células de largura; células oleíferas/mucilaginosas freqüentemente presentes (Record \& Hess, 1942; Record \& Mell, 1924; Richter, 1987).

Parênquima axial abundante é uma característica da família Lauraceae (Richter, 1987) e o tipo e a distribuição deste tecido têm sido muito utilizados na identificação dos táxons dentro da família (Callado \& Costa, 1997; Richter, 1987). Nas espécies descritas neste trabalho foi observada a presença conspícua de parênquima axial, representado pela combinação dos tipos vasicêntrico e unilateral em Nectandra leucantha; vasicêntrico, aliforme e confluente em Nectandra rigida; vasicêntrico, unilateral, aliforme e confluente em Nectandra puberula.

O tipo de placa de perfuração é uma característica anatômica de grande significância na identificação das Lauraceae (Richter, 1987). Nectandra puberula e Nectandra rigida apresentaram simultaneamente placas de perfuração simples e escalariformes. Em Nectandra leucantha observou-se a presença de placas de perfuração simples associadas a placas de perfuração escalariformes e irregulares. A presença de placas de perfuração de forma irregular é restrita a poucas espécies como, por exemplo, Claoxylon purpureum (Euphorbiaceae), Sorbus commixta, S. pteridophylla, Photinia beauverdiana e $P$. villosa (Rosaceae) (Hayden \& Hayden, 2000;
Zhang \& Baas, 1992). Todavia, nenhuma importância taxonômica tem sido atribuída a este caráter, que normalmente é encarado como uma transição entre placa de perfuração simples e escalariforme (Meylan \& Butterfield, 1975).

A presença de células oleíferas/ mucilaginosas é comumente referida para a maioria das espécies de Lauraceae (Richter, 1987). Entretanto, a ausência destas células pode ser observada em algumas espécies como Beilschmiedia emarginata, B. rigida (Callado \& Costa, 1997); B. tawa, Aniba guianensis, A. robusta (León \& Espinoza de Pernía, 2000a, b) e Ocotea rodiei (Richter, 1987). Dentre as espécies estudadas neste trabalho, Nectandra leucantha e $N$. rigida não apresentaram células oleíferas/mucilaginosas, enquanto que em $N$. puberula foi observada a presença de substâncias lipídicas e pécticas em idioblastos, tanto do parênquima axial como radial. A presença simultânea de células oleíferas e mucilaginosas no lenho de uma mesma espécie é um caráter limitado a algumas poucas dicotiledôneas (Richter, 1987).

A associação entre a forma e o tamanho das pontoações intervasculares e raiovasculares é considerada por Richter (1987) um dado importante na identificação taxonômica das Lauraceae. Nectandra leucantha e $N$. puberula apresentaram pontoações intervasculares alternas de formato poligonal, enquanto que $N$. rigida apresentou pontoações intervasculares alternas de formato 
circular. Todas as espécies analisadas apresentaram pontoações intervasculares medindo entre 7-15 $\mu \mathrm{m}$ e pontoações raiovasculares classificadas na categoria $B$ de Richter (1987), por apresentarem forma e tamanho similares às pontoações intervasculares, além de aberturas arredondadas e alongadas nos sentidos horizontal, vertical ou diagonal.

Rohwer (1993) observou em 60\% das espécies de Nectandra a presença de cristais de oxalato de cálcio no parênquima radial. Castiglioni (1962) referiu a presença de cristais estilóides nos raios de Nectandra saligna. Richter (1980) ressalta a importância diagnóstica e taxonômica de inclusões inorgânicas nos diferentes táxons da família. Em Nectandra leucantha, N. puberula e $N$. rigida não foram observadas inclusões inorgânicas na estrutura lenhosa.

A análise comparativa reunindo as três espécies estudadas e as seis outras descritas na literatura (Alves de Pinho, 1968; Castiglioni, 1962; Luchi, 1998), reforça a grande uniformidade estrutural em nível genérico. Contudo, foi possível estabelecer diferenças significativas entre a estrutura anatômica do lenho dessas nove espécies. Os caracteres anatômicos que se mostraram mais efetivos para a segregação das espécies referem-se ao tipo e distribuição do parênquima axial, formato das pontoações intervasculares, presença de cristais e de células oleíferas/ mucilaginosas.

\section{AGRADECIMENTOS}

Ao Instituto de Pesquisas Jardim Botânico do Rio de Janeiro e ao Programa Mata Atlântica por possibilitarem o desenvolvimento deste trabalho. Ao Conselho Nacional de Desenvolvimento Científico e Tecnológico CNPq pela concessão da bolsa de estudo. Às Dras. Claudia Franca Barros e Cecília Gonçalves Costa pelas valiosas sugestões e revisão do texto. Ao pesquisador Sebastião José da Silva Neto pela ajuda na coleta do material botânico. À tecnologista de madeira
Inês Cosme Neves Grillo e ao técnico de laboratório Paulo Rogério Ferreira Dias pela ajuda no processamento dos materiais, além da confecção das lâminas e cópias fotográficas.

\section{REFERÊNCIAS BIBLIOGRÁFICAS}

Alves de Pinho, R. 1968. Estudo anatômico do lenho secundário de três espécies florestais do estado de São Paulo - Brasil. Arquivos de Botânica do Estado de São Paulo 4: 137-140.

Barros, C. F. et al. 1997. Madeiras da Mata Atlântica - Anatomia do Lenho de Espécies Ocorrentes nos Remanescentes Florestais do estado do Rio de Janeiro - Brasil. Rio de Janeiro. Programa Mata Atlântica - Instituto de Pesquisas Jardim Botânico do Rio de Janeiro. Vol. 1. 86p.

Burger, L. M. \& Richter, H. G. 1991. Anatomia da Madeira. São Paulo. Nobel. 154 p.

Callado, C. H. \& Costa, C. G. 1997. Wood anatomy of some Anaueria and Beilschmiedia species (Lauraceae). IAWA Journal 18 (3): 247-259.

Castiglioni, J. A. 1951. Lauraceas Argentinas (1). I. Genero Nectandra. Boletin de la Sociedad Argentina de Botanica 4 (1; 2): 67-94.

1962. El leño secondario de las especies argentinas de Nectandra. Revista de Investigaciones Forestales 3 (1): 1-15 + 5 plates.

Chacón, I. M. \& Fournier, L. 1987. Distribución del género Nectandra (Lauraceae) en Costa Rica. Revista de Biologia Tropical 35 (1): 155-157.

Coradin, V. T. R. \& Muñiz, G. I. B. de 1991. Normas e Procedimentos em Estudos de Anatomia de Madeira: I. Angiospermae. II. Gimnospermae. Laboratório de Produtos Florestais - Série Técnica 15: 1-19.

Gottlieb, O. R. 1972. Review article chemosystematics of the Lauraceae 
Phytochemistry 11: 1537-1570.

Guedes-Bruni, R. R. 1998. Composição, estrutura e similaridade florística de dossel em seis unidades fisionômicas de Mata Atlântica no Rio de Janeiro. Tese de Doutorado, USP, São Paulo. 231 p.

Hayden, W. J. \& Hayden, S. M. 2000. Wood anatomy of Acalyphoideae (Euphorbiaceae). IAWA Journal 21 (2): 213-235.

IAWA Committee. 1989. List of microscopic feature of hardwood identification. IAWA Bulletin 10 (3): 219-332.

Jensen, D. H. 1962. Botanical Histochemistry (Principles and Practice). San Francisco, W. H. Freeman and Company, VI. 408 p.

Johansen, D. A. 1940. Plant Microtechnique. New York, McGraw - Hill Book Company, XI. 523 p.

Klein, R. M. 1974. Importância e fidelidade das Lauraceae na "Formação Araucária" do Estado de Santa Catarina. Insula 7: 1-19.

León, W. J. \& Espinoza de Pernía, N. 2000a. Estudio anatômico del leño de ocho especies del género Aniba Aublet (Lauraceae). Revista Forestal Venezolana 44 (1): 37-46. . 2000b. Estudio anatômico del leño de siete especies del género Beilschmiedia Nees (Lauraceae). Revista Forestal Venezolana 44 (1): 47-56.

Luchi, A. E. 1998. Periodicidade de crescimento em Hymenaea courbaril L. e anatomia ecológica do lenho de espécies de mata ciliar. Tese de Doutorado, USP, São Paulo. 236 p.

McLean, R. C. \& Cook, W. R. I. 1958. Plant Science Formulae. London, MacMillan \& Company Ltd. 205 p.

Metcalfe, C. R. 1987. Anatomy of the Dicotyledons. $2^{\mathrm{a}}$. ed. Oxford. Claredon Press. III. 223 p.

Meylan, B. A. \& Butterfield, B. G. 1975.
Occurrence of simple, multiple and combination perforation plates in the vessels of New Zealand woods. New Zealand Journal of Botany 13: 1-18.

Record, S. J. \& Hess, R. W. 1942. American timbers of the family Lauraceae. Tropical Woods 69: 7-33.

\& Mell, C. D. 1924. Timbers of Tropical America New Haven, Yale Univers. Press. 610 p.

Richter, H. G. 1980. Occurrence, morphology and taxonomic implications of crystalline and siliceous inclusions in the secondary xylem of the Lauraceae and related families. Wood Science and Technology 14: 35-44. 1987. Mature Secondary Xylem. In: Metcalfe, C. R. 1987. Anatomy of the Dicotyledons $2^{\text {a }}$. ed. Oxford, Claredon Press. III. 162-171 p.

Rizzini, C. T. 1971. Plantas do Brasil: Árvores e Madeiras Úteis do Brasil: Manual de Dendrologia Brasileira. São Paulo. Edgar Blücher/EDUSP. 294 p.

Rohwer, J. G. 1993. Lauraceae (Nectandra). Flora Neotropica 60: 1-332.

Sass, J. E. 1958. Elements of Botanical Microtechnique. New York - London, McGraw - Hill Book Company lnc. 222 p.

Stern, W. L. 1954. Comparative anatomy of xylem and phylogeny of Lauraceae. Tropical Woods 100: 1-75.

Van der Werff, H. 1991. A key to the genera of Lauraceae in the New World. Annals of the Missouri Botanical Garden 78: 377-387.

\& Richter, H. G. 1996. Toward an improved classification of Lauraceae. Annals of the Missouri Botanical Garden 83: 409-418.

Zhang, Shu-Yin \& Baas, P. 1992. Wood anatomy of trees and shrubs from China. III. Rosaceae. IAWA Bulletin 13 (1): 21-91. 